\title{
Realisation of the mechanical characteristic of a series excited DC machine in the drive with converter - fed induction machine
}

\author{
Grzegorz Skarpetowski ${ }^{1, *}$ \\ ${ }^{1}$ Ret. Technical University, Kraków, Poland
}

\begin{abstract}
A control algorithm for converter-fed induction machines, which allows the operation of the drive along of mechanical characteristic similar to the characteristic of series-excited direct current machine especially suitable for adhesion traction drives, is presented.
\end{abstract}

\section{Introduction}

Converter-fed induction machines are at present time in the modern energy economical traction drives widely used. In that application, which is still in continuous development are problems in the mechanical part of the drive observed, [1, 2, 3, 4], [8], which are connected with well-known problems of slip and slide dynamic states. The problems are still waiting for final solution. The comparison of properties of old fashioned drives with series-excited DC motor characteristic allows showing of the principal difference between the series and the shunt or separately excited motors. The induction machine belongs to the second group of electrical machines. The rapid change of the developed torque on the mechanical characteristic of induction machine in the region of normal operating points, generates an enormous dynamical stress, not only for electrical, but for the mechanical part of the traction channel, too. Especially difficult, for the control circuits, is to try to avoid, the suddenly change from motoring operation into the braking operation, due to change of wheel speed of the drive. The suddenly sign change of the developed torque, reduce the traction force of the drive and cause overload and fast destruction and devastation of the mechanical parts of the drive.

\section{Presentation of the "series excitation" control method of induction machine}

The analytical description of the relations used in the control method resulting in creation of series-excited machine properties is based at modified equivalent circuit of induction machine. The classical Kloss equivalent circuit doesn't specially support the main control quantities allowing simple derivation of the relevant relations which are valid for a series-excited mechanical characteristic of induction machines. The modified equivalent circuit of the machine is shown at Fig. 1:

- $\omega_{1}$ - fundamental harmonic of stator current pulsation;
- $\omega_{2}$ - fundamental harmonic of rotor current pulsation;

- $R_{1}$ - resistance of stator windings;

- $L_{1}$ - inductance of stator windings;

- $R_{2}$ - resistance of rotor windings;

- $L_{2}$ - inductance of rotor windings;

- $L_{M}$ - main inductance of machine;

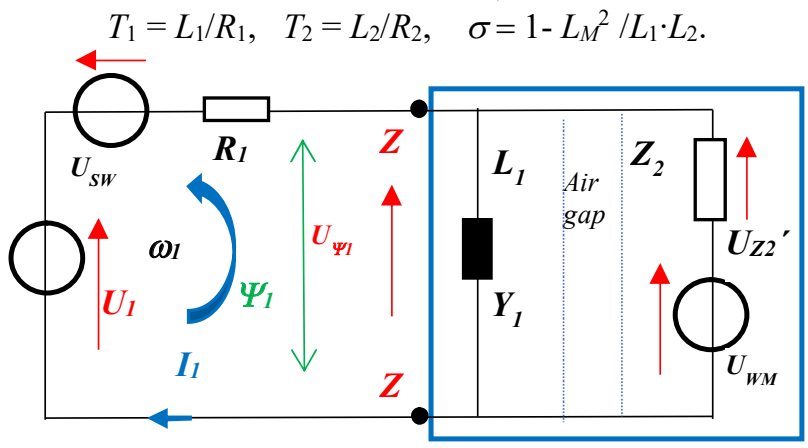

Fig. 1. Modified, valid in frequency domain for the fundamental harmonic of the converter output voltage, equivalent circuit of induction machine. The voltage, current and flux values are presented in the form of the complex amplitudes. In the closed electrical circuit, in frequency domain, the mechanical switch is replaced by equivalent voltage source $U_{S W}$.

Presented equivalent circuit is used to emphasise the main role of the flux linkage $\Psi_{1}$ of the stator winding in the analytical description of induction machines. The value of stator flux linkage $\Psi_{1}\left(\omega_{1}, \omega_{2}\right)$ which is a function of converter output voltage fundamental harmonic and pulsation in stator and rotor, allows simple description of voltage drops in rotor equivalent circuit. In the rotor part of modified equivalent circuit, a voltage sink has been introduced. The voltage sink allows explaining the energy flow in the induction machine. The power consumed by the voltage sink is equal to the mechanical power of the machine. The voltage sink can be understood as the equivalent source of the mechanical power, current $I_{2}$ in the voltage sink as equivalent of torque and voltage $U_{Z 2}$ as equivalent of angle velocity of

\footnotetext{
* Corresponding author: skarpetowski@hispeed.ch
} 
the machine shaft. The equivalent circuit in Fig. 1 can be analytically described with following $U_{1} / I_{1}$ immittance.

$$
\frac{U_{1}\left(\omega_{1}, \omega_{2}\right)}{I_{1}\left(\omega_{1}, \omega_{2}\right)}=R_{1} \cdot \frac{1-\sigma \cdot \omega_{1} \cdot T_{1} \cdot \omega_{2} \cdot T_{2}+j \cdot\left(\omega_{1} \cdot T_{1}+\omega_{2} \cdot T_{2}\right)}{1+j \cdot \omega_{2} \cdot T_{2}}
$$

The stator susceptance is described by equation:

$$
Y_{1}\left(\omega_{1}, \omega_{2}\right)=\frac{1}{j \cdot \omega_{1} \cdot L_{1}}
$$

Admittance of the rotor equivalent circuit is described by equation:

$$
Y_{Z 2}\left(\omega_{1}, \omega_{2}\right)=\frac{T_{2}}{L_{1}} \cdot \frac{(1-\sigma)}{1+j \cdot \sigma \cdot \omega_{2} \cdot T_{2}}
$$

Three important voltage drops in the equivalent scheme of induction machine depends in very characteristic way of the stator flux linkage $\Psi_{1}\left(\omega_{1}, \omega_{2}\right)$. The voltage on magnetic part of equivalent circuit, without voltage drop on stator resistance $R_{1}$ depends on flux and additionally of the stator voltage pulsation $\omega_{1}$ :

$$
U_{\psi 1}\left(\omega_{1}, \omega_{2}\right)=j \cdot \omega_{1} \cdot \psi_{1}\left(\omega_{1}, \omega_{2}\right)
$$

Voltage on the rotor equivalent voltage sink depends of angle velocity of the machine shaft $\omega_{M}=\omega_{1}-\omega_{2}$ :

$$
U_{W M}\left(\omega_{1}, \omega_{2}\right)=j \cdot \omega_{M} \cdot \psi_{1}\left(\omega_{1}, \omega_{2}\right)
$$

Voltage drop on rotor passive elements depends on the slip pulsation $\omega_{2}$ :

$$
U_{Z 2}\left(\omega_{1}, \omega_{2}\right)=j \cdot \omega_{2} \cdot \psi_{1}\left(\omega_{1}, \omega_{2}\right)
$$

Stator current can be described by equation:

$$
I_{1}\left(\omega_{1}, \omega_{2}\right)=\frac{\psi_{1}\left(\omega_{1}, \omega_{2}\right)}{L_{1}} \cdot \frac{1+j \cdot \omega_{2} \cdot T_{2}}{1+j \cdot \sigma \cdot \omega_{2} \cdot T_{2}}
$$

And rotor current achieves the value:

$$
I_{2}\left(\omega_{1}, \omega_{2}\right)=j \frac{\psi_{1}\left(\omega_{1}, \omega_{2}\right)}{L_{1}} \cdot \frac{(1-\sigma) \cdot \omega_{2} \cdot T_{2}}{1+j \cdot \sigma \cdot \omega_{2} \cdot T_{2}}
$$

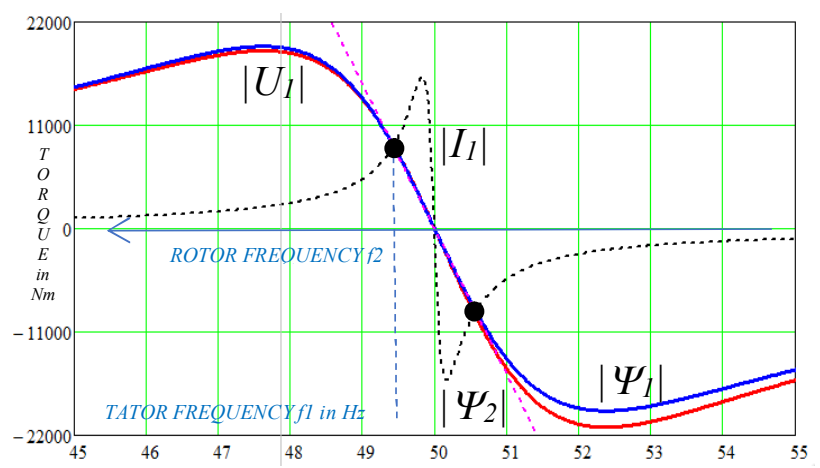

Fig. 2. Selected types of mechanical characteristic of induction machines used at present in the traction system drives. Broad use found the characteristics $\left|\Psi_{1}\right|=$ const. and $\left|U_{1}\right|=$ const. In the practical operating range 3 of the 4 characteristics are very similar. The practical operating range of the machine is located between nominal operating point in motoring and braking. $\left|\Psi_{1}\right|$ =const., $\left|\Psi_{2}\right|=$ const. and $\left|U_{1}\right|=$ const. are mechanical characteristics of shunt excited machines. The derivate $d M / d f_{1}$ of these characteristics has very large values. Such behaviour of the traction machine is very unfavourable to the characteristics of the traction drives.

The only chance to improve the behaviour of induction motor drives is to approach of the characteristic of series-excited direct current machine. In that machine, the increase of the angle speed of rotor does not lead to the change of torque sign. Such DC drives do not lose the ability to pull. The solution of the presented problems, observed in converter traction drive systems, seem to lie in the change of the present time used control algorithm of converter-fed induction machines. The mechanical behaviour similar to the series-excited DC machines can be generated by converter-fed induction motor drives too. There is also the important, additional possibility to change the inclination of the mechanical characteristic in any way. The equation [6] describing the change of the torque along the "series" characteristic of a converter-fed induction machine, as a function of stator and rotor frequency, by constant value of stator voltage is as follow:

$\operatorname{ME}\left(u, \omega_{1}, \omega_{2}\right)=\frac{\frac{3 \cdot p}{2 \cdot R_{1}} \cdot|u|^{2} \cdot(1-\sigma) \cdot T_{1} \cdot \omega_{2} \cdot T_{2}}{\left(1-\sigma \cdot \omega_{1} \cdot T_{1} \cdot \omega_{2} \cdot T_{2}\right)^{2}+\left(\omega_{1} \cdot T_{1}+\omega_{2} \cdot T_{2}\right)^{2}}$

The position of the induction machine operating point is controlled by $\left|I_{1}\right|=$ const., $\omega_{2}=$ const. or $\omega_{2}$ and $\left|I_{1}\right|$ = var:

- $|u|$ - the module of amplitude of stator voltage;

- $\quad p$ - number of magnetic poles of stator windings.

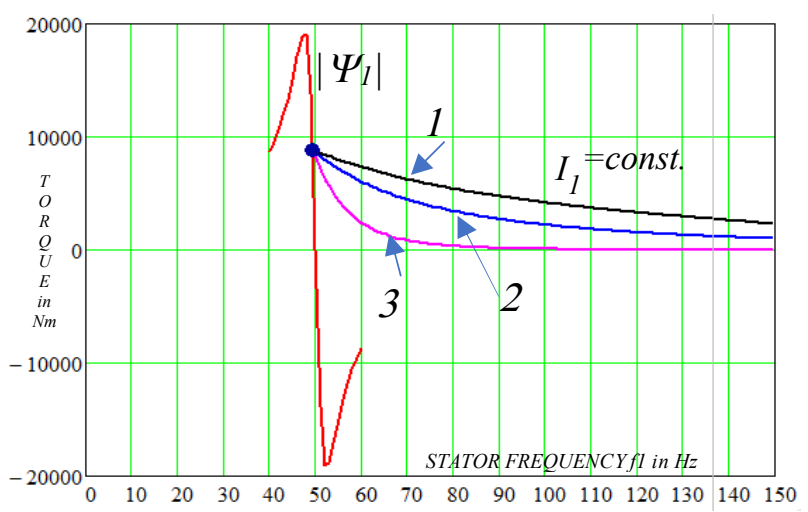

Fig. 3. Three examples of "series" mechanical characteristics realised in drive with a converter-fed induction machine, similar to the characteristic a series-excited DC machine, are shown on the background of the characteristic $\left|\Psi_{1}\right|=$ const. The series characteristic marked with number 1 can be generated by control method $\left|I_{1}\right|=$ const. The characteristic 2 can be achieved with control method $f_{2}=$ constant. Characteristic 3 presents the possibility of the additionally change of the characteristic inclination.

Comparison of the characteristics $\left|\Psi_{1}\right|=$ const. and $\left|I_{1}\right|=$ const. carried out on the Figure 4 highlights the suitability of the presented control method for traction 
drives with converter-fed induction machines. The results of the comparison have been presented below.

Properties of the mechanical characteristic of induction machine driven with constant value of flux linkage:

- torque reversal possible even with small change of wheel speed;

- $\quad$ high dynamic loading of the mechanics;

- $\quad$ sudden medium frequency relief and load the elastic elements of the coupling and transmission;

- great steepness of the mechanical characteristic;

- $\quad$ significant reduction of the force transmitted from the motor to the rails in slip and slide condition;

- lower load and minor wear on the wheels of the vehicle;

- $\quad$ large values of derivation $\frac{\Delta M p}{\Delta f m}=\frac{M n}{f 2 n}$

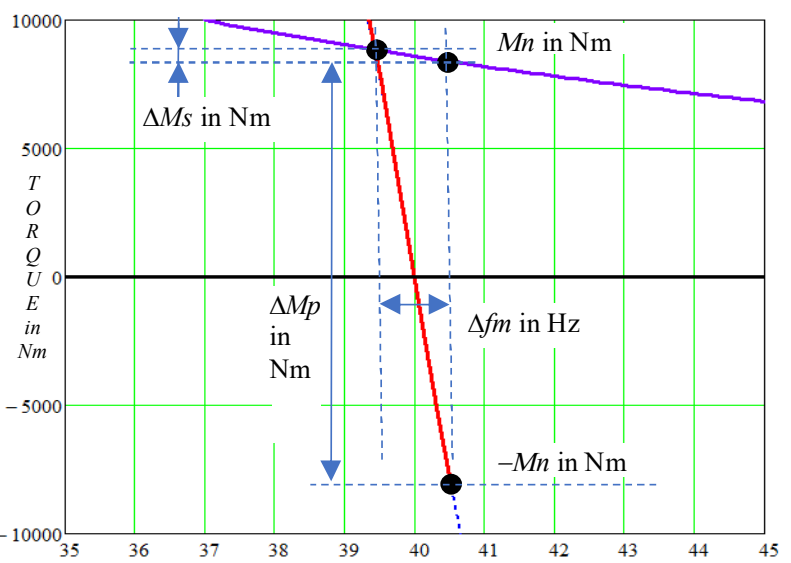

Fig. 4. A difference in the inclination of the mechanical characteristics, caused by using of two different control methods in the same drive with converter-fed induction machine. The very steep characteristic curve is formed by the method $\left|\Psi_{1}\right|=$ const. The flat characteristic, corresponds to the characteristic of a series-excited DC machine.

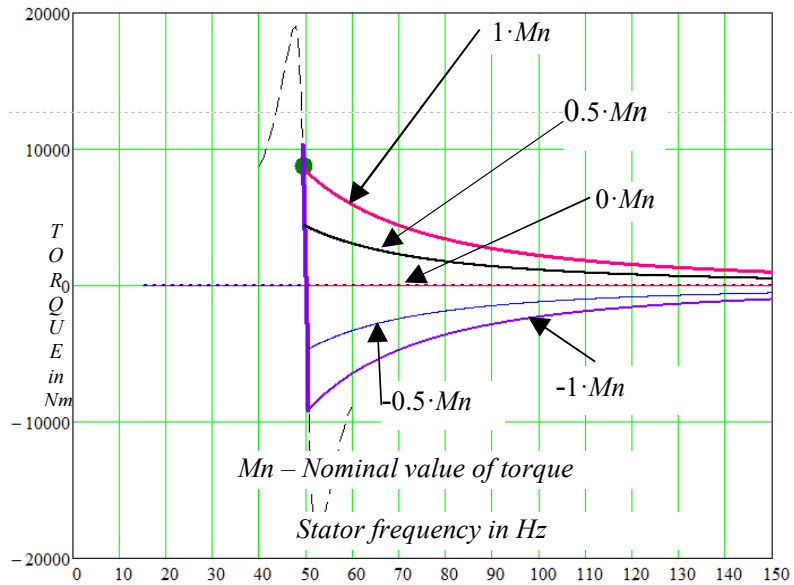

Fig. 5. Controllability of the "series-excited" characteristics of converter-fed induction machines is presented. The characteristics can be varied by change of the stator current or/and of the rotor frequency.

Properties of the mechanical characteristic of the induction machine operated along a series mechanical characteristic of DC motors:
- no change in the sign of the drive torque even with a larger increase of the rotor angular speed;

- even in the slip or slide conditions, the drive, which is in the driving mode remains in the driving and the drive which is in the braking operation remains in the brakes;

- reduction of the dynamic stress of elastic elements in power transmissions channel;

- small steepness of the mechanical characteristic;

- larger wear of the wheels, but the vehicle can pull better;

- $\quad$ small values of derivation $\frac{\Delta M s}{\Delta f m}=\frac{0,1 \cdot M n}{f 2 n}$.

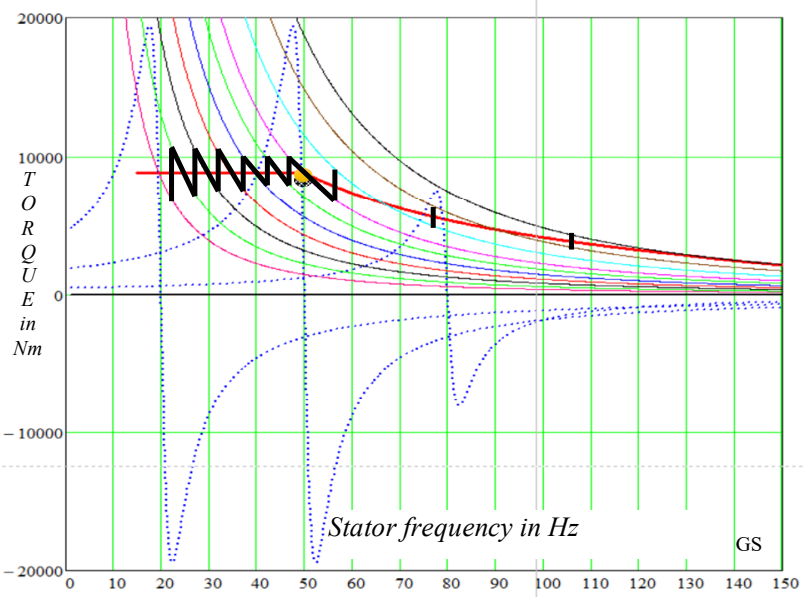

Fig. 6. Application of the "series-excited" characteristics of converter-fed induction machine in control systems comparable with the "tap changer" voltage control used in conventional series-excited DC machine.

The behaviour of series excited, convertor supplied induction machine, in slip conditions, causes the reduction of the torque as result of constant voltage and increasing stator frequency. See Figures 7 and 8.

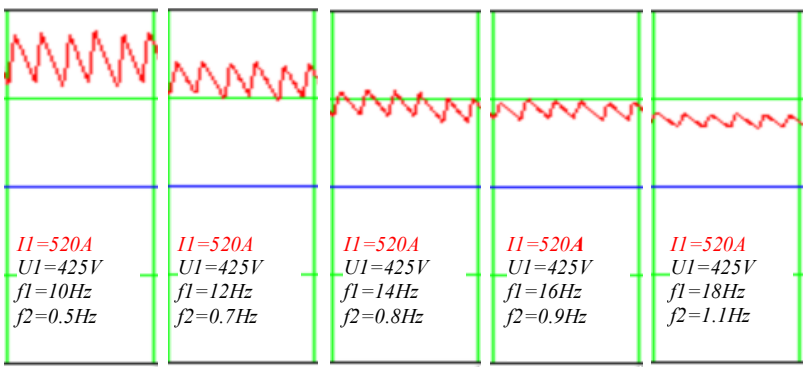

Fig. 7. Slip conditions in motoring state of the traction drive. The reduction of the torque starts as reaction on the rotor angular velocity increase of the induction machine. The change of the torque with control method which keeps previous constant value of the stator current module is presented. Current controller is increasing stator frequency to counteract the sudden current reduction. The stator voltage remains depending on vehicle speed on constant value. The difference between wheel velocity and vehicle velocity has no influence on the value of stator voltage amplitude. 


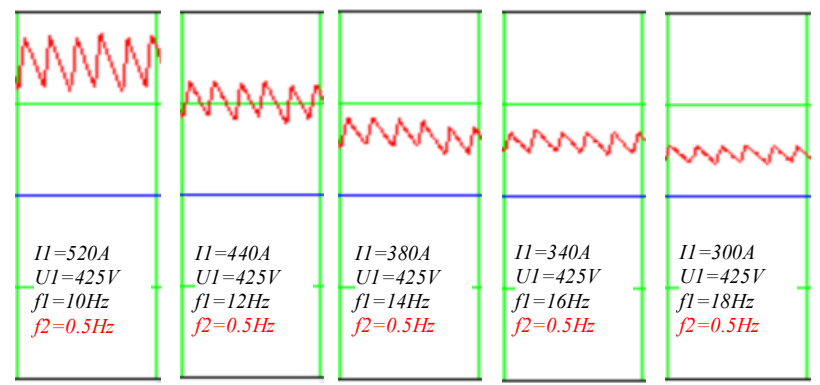

Fig. 8. Slip conditions in motoring state of the traction drives. The reduction of the torque starts as reaction on the rotor angular velocity increase of the induction machine. The change of the torque with control method which is keeping constant value of the rotor frequency is presented. The frequency controller increases the stator frequency to avoid suddenly change of rotor frequency. The controller adds the previous constant value of rotor frequency to the mechanical frequency of the rotor. Due to the simultaneously occurring reduction of stator current in function of stator frequency, the torque decreases faster than by constant current control method.

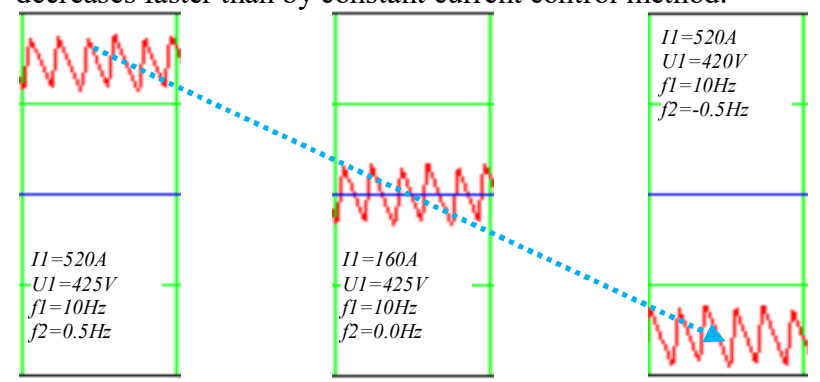

Fig. 9. Figure shows the progress of switching from motoring operation to braking operation which is carried out with constant value of stator flux linkage. $\left|\Psi_{1}\right|=$ const. The harmonics of the torque, which do not depend on average value of torque, are in all operation state nearly constant. The mechanical elements of the power transmission channel are extremely overloaded in all operating states.

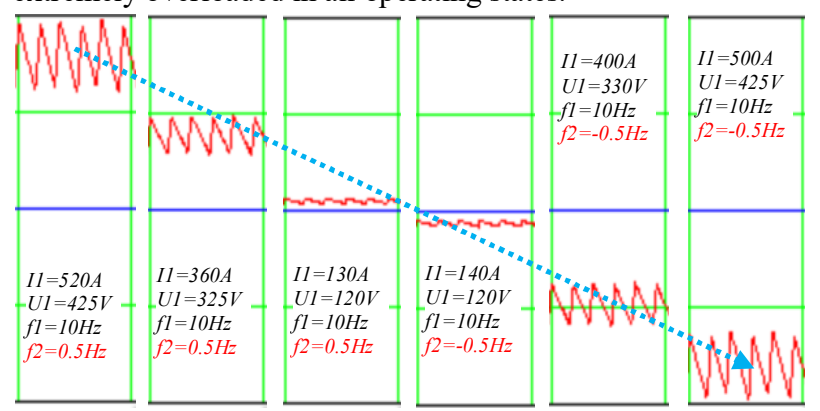

Fig.10. Figure shows the progress of switching from motoring operation to braking which is carried out by switching between mechanical characteristics of a "series-excited" induction machine. The switching between possible mechanical characteristic can be made by change of stator flux linkage or stator voltage amplitude. In zero crossing of torque average value the harmonics of torque are reduced to zero.

\section{Conclusion}

The described control method can be implemented in vehicles with multi converter-fed drive systems with induction machines. Such drive systems are commonly used in traction system with adhesion power transmission.

The control method allows the realisation of mechanical characteristic of separately-fed induction machine drives similar to the mechanical characteristic of series-excited direct current motor.

During occurring of fast slip or slide condition in the drive, the sign of the torque developed through the machine does not change.

The drive can stationary be operated in the range of macro slip.

The presented method is based on common control of the stator voltage fundamental harmonic which is equal for all motors of the vehicle. The value of the amplitude of the voltage is derived in suitable way from the value of vehicle speed.

The method uses the well-known concept of operating point control trough appropriate control of stator frequency, but the frequency control is made for each motor completely separate.

Each drive is running with own mechanical velocity and with own separately controlled stator frequency.

The stator frequency control circuit can, as far as possible, change the stator frequency with use of one the algorithms listed below:

1) with constant value of stator current module,

2) with constant value of rotor frequency,

3) with custom defined simultaneously change of stator current value or/and rotor frequency.

The described control method is based on fast measurement of 3 phase current module and of the mechanical frequency which is commonly used for description of the velocity of machine shaft.

In multi drive systems the recognition of slip and slid conditions of individual axes is not necessary.

Only in the drive with single motor or in the case of slip of all wheels in multi drive systems it is necessary to recognise on time the hazardous dynamical state.

In the starting state of the drive and in very low stator frequencies where $f_{1}<\sim 4 \cdot f_{2 N}$, the value of stator current and the value of the torque is controlled directly by stator voltage.

The traction properties of the adhesion drive which are controlled by the presented algorithm will be essentially improved in comparison to the control methods used today.

The state of development in the field of traction drive control is displayed in the specified references.

\section{References}

1.R. Frösch, DP. Verfahren zur Drehmomentregelung einer Drehfeldmaschine. DE 19530622 A1 (1995)

2. P. Good, DP. Verfahren zur Regelung einer Drehfeldmaschine. DE 4215917 A1 (1992)

3.E. Grossmann, WIPO. Control device and method for jointly controlled asynchronous machines of a motor vehicle. WO 2016/119948

4. A. K. Kumar, US. Method of inhibiting wheel slip in an electric alternating current induction motor powered vehicle. 5,480,220 (1996) 5. G. Skarpetowski, US. Method of Controlling Electric Vales of a converter. Nr. 5,331,537 (1994)

6. G. Skarpetowski, Przetworniki i przeksztattniki energii w napędach trakcyjnych. Kraków: PIT ISBN 978-83-86219-86-5 (2016)

7.G. Skarpetowski, Verfahren zum Betrieb einer elektrischen Asynchronmaschine. Patent pending, EP 17150554.8 (2017)

8. N. Tomohito, Controller for electric vehicle. EP JPO, 2002095111 (2000) 